\title{
Are Methylenetetrahydrofolate Reductase (MTHFR) Gene Polymorphisms C677T and A1298C Associated with Higher Risk of Pediatric Migraine in Boys and Girls?
}

\author{
Anna-Liisa Lorenz1, Tiina Kahre',3, Evelin Mihailov4, Tiit Nikopensius ${ }^{4}$, \\ Eno-Martin Lotman', Andres Metspalu4, Anneli Kolk²,6 \\ ${ }^{1}$ Genetic Engineering, University of Tartu, Tartu, Estonia \\ ${ }^{2}$ Department of Pediatrics, Universtity of Tartu, Tartu, Estonia \\ ${ }^{3}$ Department of Genetics, United Laboratories, Tartu University Hospital, Tartu, Estonia \\ ${ }^{4}$ Estonian Genome Centre, University of Tartu, Tartu, Estonia \\ ${ }^{5}$ Faculty of Medicine, University of Tartu, Tartu, Estonia \\ ${ }^{6}$ Department of Child Neurology, Children's Clinic, Tartu University Hospital, Tartu, Estonia \\ Email: annaliisalorenz@gmail.com, anneli.kolk@kliinikum.ee
}

Received 9 April 2014; revised 26 May 2014; accepted 7 June 2014

Copyright (C) 2014 by authors and Scientific Research Publishing Inc.

This work is licensed under the Creative Commons Attribution International License (CC BY).

http://creativecommons.org/licenses/by/4.0/

(c) (i) Open Access

\section{Abstract}

Introduction: Women have been reported to have a higher risk for migraine. The pathogenesis of migraine is known to be related to genetic risk factors such as the presence of common polymorphisms C677T (rs1801133) and A1298C (rs1801131) in the MTHFR gene. The aim of the study was to examine the role of these two MTHFR polymorphisms as risk factors for pediatric migraine and examine the gender-specific differences. Methods: 56 patients $(M=26 ; F=30)$ with migraine were randomly selected from Tartu University Hospital Children's Clinic. 29 patients had migraine with aura $(M=13, F=16)$ and 27 migraine without aura $(M=13, F=14)$. The average age of the patients was 12.7 yrs $(S D=3.3)$. The control group consisted of 168 healthy people $(M=78, F=90)$, ages 22 - 35 yrs (average $29.2 \pm 3.4$ ). Results: Among patients with aura, girls had higher frequency of A1298C and C677T mutations than boys, but not with statistical significance (minor allele frequency 0.406 and $0.231, p=0.16$; minor allele frequency 0.313 and $0.269, p=0.72$; respectively). In the migraine without aura group, girls had higher frequency in C677T (minor allele frequency 0.357 vs $0.231, p=0.31$ ) than boys. Comparing the migraine group with controls, higher frequencies of minor allele of $\mathrm{A1298C}$ and $\mathrm{C677T}$ in female patients were found $(\mathrm{p}=0.63$ and $\mathrm{p}=$ 0.32 respectively). In contrast, the C677T minor allele occurred in male controls with higher frequency $(p=0.34)$. Conclusion: Our results indicate a possible contribution of common MTHFR 
gene polymorphisms to migraine risk in children. $91 \%$ of children with migraine carried the variant alleles. Among girls, MTHFR polymorphisms occurred more frequently than among boys, but these differences were not statistically significant. We found that girls with migraine (with and without aura) showed an increased prevalence of C677T polymorphisms.

\title{
Keywords
}

\author{
Migraine, MTHFR Gene Polymorphisms, Children
}

\section{Introduction}

Migraine is a common neurological disorder that affects $~ 10 \%$ of the world's population [1]; mainly women are affected [2]. Children with this disorder are also highly prevalent (3.5\% - 5\%) [3] and it is a major reason for absence from school, decreased academic level, higher rate of recurrent illnesses, etc. Migraine headache can also be associated with other symptoms such as nausea, vomiting, photo- and phonophobia [4]. This disorder is classified in two subtypes: migraine with aura (MA) and without aura (MO) [5]. MA comprises nearly $25 \%$ of all migraine cases in overall migraine population [6]. It is described by a disturbance of motor and visual activities that lasts 20 to 30 minutes before the migraine attack [7]. MO makes up 70\% of all migraine cases [6] and its clinical features differ between adults and children [8]. Migraine, particularly MA, is associated with a higher risk of ischemic stroke (IS) in young women [9] [10]. Possible mechanisms predisposing migraine patients to IS may be vascular, neuronal or related to coagulation abnormalities and genetics [11]. Schurks et al. showed [12] that MA doubles the risk of ischaemic stroke, but MO—-the most common type of migraine-is not a risk factor for stroke. With regard to genetic factors, previous studies provided evidence that the risk of ischaemic stroke in people with MA is further increased by a polymorphism in the MTHFR gene. Better phenotyping is a prerequisite for a clearer understanding of these disorders [13]. The first epidemiological indication for migraine to be risk factor for ischemic stroke was described in 1975 by the Collaborative Group for the Study of Stroke in Young Women [14]. Since then several studies have also provided the same results [15] [16].

The etiology of migraine is complex and the disorder is most likely caused by the combination of genetic and environmental risk factors [17].

The appearance of migraine and its association with functional polymorphisms in the methylenetetrahydrofolate reductase (MTHFR) gene has been extensively studied.

The gene encodes MTHFR enzyme that converts 5,10-methylenetetrahydrofolate into 5-methylenetetrahydrofolate, which is the circulating form of folate in plasma. Folate is needed for conversion of homocysteine to methionine [7]. In the presence of either homozygous or heterozygous C677T or A1298C variants of the MTHFR gene, the activity of the enzyme is downregulated, therefore homocysteine level in blood plasma increases [18] [19]. The C677T transition leads to the substitution of alanine to valine, in codon 222, which in turn leads to more thermolabile protein. Thermolability is the cause for decreased activity of the enzyme. Unlike the C677T variant, the A1298C transversion substituting glutamate to alanine in codon 429 located in the C-terminal regulatory domain will not cause the thermolability of the enzyme [20]. People with a homozygous TT genotype of C677T show a higher level of plasma homocysteine than people with a heterozygous CT genotype [21]. Individuals carrying 677TT express only about 30\% of the mean activity of the MTHFR enzyme [22]. A similar scenario has been described for the A1298C variant; however, the enzyme activity is decreased by $40 \%$ [23]. The decreased activity of the MTHFR enzyme is considered an important risk factor for migraine.

There have been many controversial findings about the association between MTHFR polymorphisms and migraine. The associations between pediatric migraine and MTHFR polymorphisms have been studied in different populations before (e.g. Italy, Croatia etc.), but not in the Estonian population. A trend for migraine was reported in Italian patients who were 677TT and 1298CC homozygous carriers [24]. In the Croatian pediatric migraine population, no statistically significant association with migraine in carriers of 677CT polymorphism was found, but a trend toward an increased risk for migraine in patients who had homozygous variant 677TT was found [25]. It is believed that associations between childhood migraine and MTHFR polymorphisms show different patterns across populations. Another significant issue is the lack of information about the frequency dis- 
tribution of MTHFR polymorphisms in boys and girls. As noted earlier, women have been reported to have higher occurrence of migraine, approximately $18 \%$ of females are diagnosed with migraine in comparison to only $6 \%$ of males [26]. Due to the higher frequency of migraine in women, the current study investigated the differences in genetic risk factors for a better understanding in the evolution of migraine from children to adults and changes in women compared to men.

The aim of the study was to examine the presence of both common MTHFR polymorphisms in the Estonian pediatric migraine population (age $\leq 18$ years) and to give the overall and gender-specific occurrence of these polymorphisms. In addition, the purpose was also to investigate the occurrence of migraine subtypes among patients.

\section{Methods}

\subsection{Patients}

The study group consisted of 56 randomly selected patients $(M=26, F=30)$ out of 182 migraine-diagnosed children who were examined in the Tartu University Hospital Children's Clinic during the period of 2011-2014. Patients with tension headache and other chronic disease were excluded from the study. The age of the patients varied between 5 to 18 yrs with an average of $12.7 \pm 3.3$ yrs. All 56 patients were diagnosed with migraine according to the International Classification of Headache Disorders. 27 patients had migraine without aura $(\mathrm{M}=$ $13, \mathrm{~F}=14)$ and 29 patients had migraine with aura $(\mathrm{M}=13, \mathrm{~F}=16)$.

\subsection{Control Group}

The control group consisted of 168 randomly selected healthy people $(\mathrm{M}=78, \mathrm{~F}=90)$. People with migraine and cerebrovascular diseases were excluded from the group. The female-to-male ratio was matched to the patients group (1:1.15). The age of control individuals ranged from 22 to 35 yrs with an average of $29.1 \pm 3.4$ yrs. The control group was selected among the gene donors in the Biobank of the Estonian Genome Centre, University of Tartu, Estonia.

\subsection{Genetic Testing}

Genomic DNA was extracted from EDTA-collected peripheral blood using standard high-salt extraction procedures [27]. Genotype analysis for MTHFR C677T and A1298C in patients was performed by PCR-RFLP analysis using HinfI and MboII restriction enzymes respectively. To detect the presence or absence of the C677T mutation in MTHFR gene 198 bp PCR fragment was amplified using following primers: C677T-sense- 5'-TGA AGG AGA AGG TGT CTG CGG GA-3'; C677T-antisense - 5'-AGG ACG GTG CGG TGA GAG AGT-3'.

The C677T introduces a new HinfI restriction site, which results in the digestion of the 198 bpamplicon into $175 \mathrm{bp}$ and $23 \mathrm{bp}$ fragments [28]. Genotyping protocol for A1298C mutation was modified from Hanson et al. [29]. For detecting A129C polymorphism, we selectively amplified the longer 256-bp fragment of the MTHFR gene by PCR using following primers: A1298C-sense - 5'-CTT CTA CCT GAA GAG CAA GTC-3' and A1298C-antisense-5'-CAT GTC CAC AGC ATG GAG-3'. The A1298C mutation abolishes an MboII restriction site. Digestion of the 256 bp fragment of the 1298AA genotype gives four fragments of 176, 30, 28 and 22 bp, whereas the 1298CC genotype results in three fragments of 204, 30 and 22 bp.

The fragments were analyzed by $2.5 \%$ agarose gel (SeaKem ${ }^{\circledR}$ LE, Lonza) electrophoresis and visualized with ethidium bromide.

Genotyping of MTHFR polymorphisms in the control group was done with Illumina Human Omni $770 \mathrm{~K}$ BeadChip in the Core Laboratory of the Estonian Genome Centre, University of Tartu, Estonia. The quality control and filtration was carried out using IlluminaGenomeStudio 3.1 and PLINK 1.07 softwares. Gene donors and migraine patients have given an informed consent to participate in this study and permission by the Research Ethics Committee of Tartu University has been issued (patients: 233/M-19).

\subsection{Statistical Analysis}

Association analysis was performed using Pearson's chi-square test. Odds ratios with 95\% confidence intervals were calculated using $\mathrm{R}$ and Terminal software. 


\section{Results}

\subsection{Patients}

3.1.1. The Frequency of MTHFR Polymorphisms in the Migraine Group

Any copy of the variant allele in either or both of these loci was found in $91 \%$ of patients: A1298C was present in 33 and C677T in 30 out of 56 patients (Table 1). Both polymorphisms in homozygous condition (1298CC and 677TT) were found in 6/56 patients, but not with simultaneous co-existence (Table 2). The most frequent combined genotype of both MTHFR polymorphisms were the 1298AC-677CC and 1298AA-677CT genotypes, in $18 / 56(32.1 \%)$ and $15 / 56$ (26.8\%) patients respectively.

\subsubsection{Gender-Specific Distribution of MTHFR Polymorphisms among Migraine Patients}

Investigating the gender-specific occurrence of these polymorphisms, there was a difference. For $1298 \mathrm{C}$ allele, the frequency was 0.333 for girls and 0.308 for boys with the OR of $1.13(\mathrm{p}=0.77)$. For 677T allele, the frequency was 0.333 for girls and 0.25 for boys with the OR of $1.5(\mathrm{p}=0.33)$ (Table 3). The occurrence of MTHFR variant alleles was higher in girls than in boys for both polymorphisms (Table 4).

Table 1. Carriers of MTHFR polymorphisms in patient and control groups.

\begin{tabular}{ccc}
\hline & Patients $(\mathbf{N}=\mathbf{5 6})$ & Controls (N = 168) \\
\hline A1298C & $58.9 \%(33)$ & $52.4 \%(88)$ \\
C677T & $53.6 \%(30)$ & $48.2 \%(81)$ \\
& Minor allele frequency & \\
A1298C & 0.321 & 0.295 \\
C677T & 0.295 & 0.292 \\
\hline
\end{tabular}

Table 2. The occurrence of combinations of A1298C and C677T in patients and controls.

\begin{tabular}{cccc}
\hline & & Patients (56) & Control group (168) \\
\hline Homozygous (1298CC) & Normal (677CC) & $5.4 \%(3)$ & $6.5 \%(11)$ \\
Heterozygous (1298AC) & Heterozygous. (677CT) & $21.4 \%(12)$ & $17.3 \%(29)$ \\
Heterozygous (1298AC) & Normal (677CC) & $32.1 \%(18)$ & $28.6 \%(48)$ \\
Normal (1298AA) & Homozygous. (677TT) & $5.4 \%(3)$ & $10.1 \%(17)$ \\
Normal (1298AA) & Heterozygous (677CT) & $26.8 \%(15)$ & $20.8 \%(35)$ \\
Normal (1298AA) & Normal (677CC) & $8.9 \%(5)$ & $16.7 \%(28)$ \\
\hline
\end{tabular}

Table 3. Gender-specific distribution of AC1298C and C677T minor alleles frequencies in migraine patients with aura and without aura.

\begin{tabular}{ccccc}
\hline & \multicolumn{5}{c}{ All migraine patients } \\
\hline Allele & Girls & Boys & p-value & OR (95\% CI) \\
\hline 1298C & 0.333 & 0.308 & 0.77 & $1.13(0.51-2.5)$ \\
$677 \mathrm{~T}$ & 0.333 & 0.25 & 0.33 & $1.5(0.66-3.43)$ \\
\hline & \multicolumn{5}{c}{ Patient swith aura } \\
\hline Allele & Girls & Boys & p-value & OR (95\% CI) \\
\hline 1298C & 0.406 & 0.231 & 0.16 & $2.28(0.72-7.23)$ \\
677T & 0.313 & 0.269 & 0.72 & $1.23(0.39-3.88)$ \\
\hline & & \multicolumn{2}{c}{ Patients without aura } & OR (95\% CI) \\
\hline Allele & Girls & Boys & p-value & $0.55(0.17-1.70)$ \\
\hline 1298C & 0.25 & 0.385 & 0.29 & $1.82(0.56-6.12)$ \\
\hline 677T & 0.357 & 0.231 & 0.31 & \\
\hline
\end{tabular}


Table 4. Distribution of A1298C and C677T genotypes in patient and control group.

\begin{tabular}{|c|c|c|c|c|c|c|}
\hline \multirow[b]{2}{*}{ A1298C } & \multicolumn{2}{|c|}{ Patients } & \multicolumn{2}{|c|}{ Controls } & Patients & Controls \\
\hline & Boys & Girls & Men & Women & \multicolumn{2}{|c|}{ All together } \\
\hline AA & 12 (46.2\%) & 11 (36.7\%) & 37 (47.4\%) & 43 (47.8\%) & 23 (41.1\%) & $80(47.6 \%)$ \\
\hline $\mathrm{AC}$ & 12 (46.2\%) & $18(60 \%)$ & 37 (47.4\%) & 40 (44.4\%) & 30 (53.6\%) & 77 (45.8\%) \\
\hline $\mathrm{CC}$ & $2(7.7 \%)$ & $1(3.3 \%)$ & $4(5.2 \%)$ & 7 (7.8\%) & $3(5.4 \%)$ & $11(6.5 \%)$ \\
\hline C677T & Boys & Girls & Men & Women & \multicolumn{2}{|c|}{ All together } \\
\hline $\mathrm{CC}$ & 15 (57.7\%) & 11 (36.7\%) & 38 (48.7\%) & 49 (54.4\%) & $26(46.4 \%)$ & 87 (51.8\%) \\
\hline $\mathrm{CT}$ & $9(34.6 \%)$ & $18(60 \%)$ & $30(38.5 \%)$ & 34 (37.8\%) & $27(48.2 \%)$ & $64(38.1 \%)$ \\
\hline $\mathrm{TT}$ & $2(7.7 \%)$ & $1(3.3 \%)$ & $10(12.8 \%)$ & $7(7.8 \%)$ & $3(5.4 \%)$ & 17 (10.1\%) \\
\hline
\end{tabular}

\subsubsection{Gender-Specific Distribution of MTHFR Polymorphisms among Migraine Subtypes}

Another important observation was the similar frequency of migraine with aura and without aura in our pediatric migraine population. Both migraine subgroups were represented similarly among boys and girls. Migraine with aura was represented in 29/56 patients $(M=13, F=16)$ and without aura in 27/56 patients $(M=13, F=14)$.

The gender-specific examination of MTHFR 1298C allele frequency in patients with aura showed differences. Girls had a higher minor allele frequency with an OR value of 2.28 (95\% CI $0.72-7.23$; $\mathrm{p}=0.16)$. MTHFR $677 \mathrm{~T}$ allele frequency in girls diagnosed with MA was quite similar to boys ( $\mathrm{p}=0.72$, OR $1.23,95 \%$ CI 0.39 3.88). However, a slight difference in frequency of $677 \mathrm{~T}$ was present in girls who were diagnosed migraine without aura $(\mathrm{MO})$ compared to boys with $\mathrm{MO}(\mathrm{OR}=1.82,95 \%$ CI $0.56-6.12, \mathrm{p}=0.31)($ Table 3$)$.

\subsection{Control Group}

3.2.1. Genotype Distribution and Allele Frequency of the MTHFR Polymorphisms in Control Group Any copy of the variant allele in either or both of the A1298C and C677T loci was found in 84\% of controls. In the control group, the carrier frequencies of both MTHFR variants were rather high: 88 out of 168 for A1298C variant and 81 out of 168 for C677T (Table 1).

\subsubsection{Genotype Distribution and Allele Frequency in Male and Female}

No statistically significant differences were found in the carrier frequencies between women and men in the control group. The frequencies of 1298AC and 677CT genotypes were almost the same in a comparison of both genders: $52.2 \%$ in women and $52.6 \%$ in men $(\mathrm{p}=0.96)$. For genotypes $677 \mathrm{CT}$ and $677 \mathrm{TT}$, a slight difference was observed: $51.3 \%$ in men and $45.6 \%$ in women; however, it was not statistically significant $(p=0.46)$.

\subsection{The Difference in Patient and Control Group Prevalence of the MTHFR 677 and 1298 Genotypes}

\subsubsection{The General Distribution}

The genotype distributions for control group and patient group were in Hardy-Weinberg equilibrium. In this study, the comparison of the combination of A1298C and C677T polymorphisms between control group and patients group was carried out to see whether the co-occurrence of both polymorphisms in one person could increase the risk for migraine in the Estonian pediatric population.

The co-existence of both polymorphisms in one individual did not show any remarkable outcomes (Table 2). Perhaps the only aspect that should be brought out is the variant wherein A1298C and C677T both had a mutation in one allele-heterozygous-heterozygous genotype condition was slightly more frequent in patients group, but not significantly, given the percentages.

The frequencies of both polymorphisms' minor alleles in patients and controls were quite similar: 0.321 vs 0.295 for A1298C and 0.295 vs 0.292 for C677T, respectively.

\subsubsection{The Distribution of MTHFR Polymorphisms between Genders}

The comparison between polymorphisms and gender-specific subgroups showed variable patterns for the presence of polymorphisms (Table 5). Adult men in the control group and boys with migraine share a similar 
Table 5. The gender-specific comparison of A1298C and C677T variant alleles between patient and control group.

\begin{tabular}{ccccc}
\hline & \multicolumn{5}{c}{ Females } \\
\hline & Patients & Controls & p-value & OR (95\% CI) \\
\hline $1298 \mathrm{C}$ & 0.333 & 0.3 & 0.63 & $1.17(0.63-2.18)$ \\
$677 \mathrm{~T}$ & 0.333 & 0.267 & 0.32 & $1.38(0.73-2.58)$ \\
\hline & & Males & & \\
\hline $1298 \mathrm{C}$ & Patients & Controls & p-value & OR (95\% CI) \\
$677 \mathrm{~T}$ & 0.308 & 0.289 & 0.79 & $1.1(0.55-2.17)$ \\
\hline
\end{tabular}

frequency of A1298C ( $\mathrm{p}=0.79, \mathrm{OR}=1.1,95 \% \mathrm{CI} 0.55-2.17)$, however, the C677T mutation prevalence rate differed to some extent but was not statistically significant ( $p=0.34$, OR $=0.71$, 95\% CI 0.35 - 1.44). Both polymorphisms were more frequent in girls with migraine than in healthy women (control group), this finding did not reach statistical significance: for C677T p = 0.32; OR = 1.38, 95\% CI 0.73 - 2.58; and for A1298C p = 0.63; $\mathrm{OR}=1.17,95 \%$ CI $0.63-2.18$.

\subsubsection{The Distribution of MTHFR Polymorphisms among Migraine Subtypes}

The MTHFR 677T allele and 677TT genotype frequencies were similar in the group of migraine with aura and migraine without aura (minor allele frequency in patients with aura 0.296 and without aura 0.293 with the p-value of 0.97 and OR of 1.02). The same prevalence of C allele and CC genotype of MTHFR A1298C was shown in both groups (minor allele frequency of 0.328 in patients with aura and 0.315 in patients without aura with a p-value of 0.89 and OR of 0.94).The distribution of MTHFR polymorphisms among different migraine subtypes showed a slight difference between patients and controls. Patients with aura had a higher frequency of A1298C mutant allele than the control group with an OR of 1.66 (minor allele frequency: 0.406 vs 0.290 , p = 0.17). As for the migraine without aura group, the A1298C occurred more frequently in controls but with no statistical significance $(p=0.57)$. C677T did not show any increased prevalence in either subgroup $(p=0.79$ and $p$ $=0.43$ respectively).

\section{Discussion}

Migraine is a complex neurovascular disorder with substantial evidence of genetic contribution. Females are two to three times more likely to experience migraine than men after reaching puberty [30]. Migraine is characterized by recurrent attacks of pulsating and unilateral head pain [31]. Migraine risk factors have been investigated in some populations but not in the Estonian population. The common polymorphisms in the MTHFR gene has been found to contribute to genetic predisposition of migraine in several studies conducted in different European populations (Italy [32], Netherlands [33], etc). Prevalence of the MTHFR 677TT genotype in the general population has been estimated at 8 to $12 \%$ [34]. In fact, there are a few studies in which the occurrence of MTHFR polymorphisms and the difference between genders in children with migraine have been examined.

The current study investigated the frequency of MTHFR C677T and A1298C polymorphisms and their association with migraine in the Estonian pediatric population. The results indicate a slight positive correlation between the carrier status of MTHFR polymorphisms and migraine headaches. 91\% of children with migraine carried the variant alleles: $1298 \mathrm{C}$ was present in 33 and $677 \mathrm{~T}$ in 30 out of 56 patients. The most frequent co-occurrence of both polymorphisms in one person was of the 1298AC-677CC and 1298AA-677CT genotypes, in 18/56 (32.1\%) and 15/56 (26.8\%) patients, respectively. The heterozygous-heterozygous genotype condition was slightly more frequent in the patients group compared with controls, but not significantly. In the control group the percentage of variant allele of either polymorphism was 84 . The carrier frequencies of the control group for both MTHFR variants were rather high: 88 out of 168 people for A1298C and 81 out of 168 people for C677T. In the migraine subjects the frequency of A1298C (58.9\%) and C677T (53.6\%) was higher compared with controls (52.4\% vs 48.2\%, respectively), but these differences were not statistically significant. One reason for this could be the small sample size, or these polymorphisms might appear as a more substantial risk factor for migraine in other populations. Bottini et al. stated that a slight trend towards an increased risk for migraine 
was present in people who carried the homozygous variant on mutant A1298C or C677T in the Italian population [24]. In the Croatian pediatric migraine population, no statistically significant association with migraine was found, but a trend toward an increased risk for migraine in patients with 677TT genotype was revealed [25]. Oterino et al. and Ferro et al. found no association of the TT-genotype in Spanish and Portuguese migraineurs, respectively [35] [36]. In our study both polymorphisms in homozygous condition (either 1298CC or 677TT) were found in only 6/56 patients (not with simultaneous co-existence) and did not show a remarkable association with increased risk for migraine. An et al. claimed that MTHFR C677T variant might be an ethnic-specific polymorphism with variable carrier frequencies, which may explain the different occurrences in different populations [17].

Investigating the gender-specific occurrence of these polymorphisms is quite unique due to the shortage of analogous researches. Comparison of the prevalence of MTHFR polymorphisms between boys and girls showed higher frequencies of MTHFR variant allele(s) in girls for both polymorphisms. Again, the differences between girls and boys in the distribution of carrying MTHFR $1298 \mathrm{C}$ and $677 \mathrm{~T}$ variant alleles were not statistically significant. However, the prevalence of 677T allele was 1.5 times higher in girls. Women are expected to be more frequently affected by migraine and the higher frequency of both polymorphisms among girls with migraine may suggest that these polymorphisms, especially C677T, could be risk factors for migraine; this is an important finding in our study. Comparing migraine girls and female control group data we found a higher tendency for both polymorphisms with increased minor allele frequencies of A1298C and C677T in the migraine group. Such differences between male patients and the control group did not appear. To the contrary, male controls had a higher frequency of C677T variant alleles, which does not attain statistical significance.

An interesting finding was the equal distribution of migraine subtypes in our randomly selected study group. 29 patients out of 56 had migraine with aura and 27 had migraine without aura. Several studies have shown a significantly higher frequency for migraine without aura, which makes up $70 \%$ of all migraine cases [6] [17] [37]. These findings were not in accordance with our findings in the Estonian pediatric migraine population; the frequency of both subtypes was almost the same. In addition, the MTHFR 677T allele and 677TT genotype frequencies were similar in the group of migraine with aura and migraine without aura. The same prevalence of $\mathrm{C}$ allele and CC genotype of MTHFR A1298C was also found in both groups. Girls within the MA group demonstrated higher frequency of MTHFR 1298C allele (OR 2.28) and girls within the MO group a slightly higher frequency of $677 \mathrm{~T}$ allele $(\mathrm{OR}=1.82)$ compared to boys.

In conclusion, we did not observe statistically significant differences in the occurrence of MTHFR polymorphisms in Estonian pediatric migraine patients. However, our data suggest the trend that MTHFR genepolymorphisms may influence susceptibility to migraine in children. Among girls MTHFR polymorphisms occurred more frequently than in boys, but these differences were not statistically significant. We found that girls with migraine (with and without aura) have increased prevalence of C677T.

Further studies are needed to better characterize the association of MTHFR with migraine in children and potential vitamin treatment in pediatric migraine patients.

\section{References}

[1] Kara, I., Sazci, A., Ergul, E., Kaya, G. and Kilic, G. (2003) Association of the C677T and A1298C Polymorphisms in the 5,10Methylenetetrahydrofolate Reductase Gene in Patients with Migraine Risk. Molecular Brain Research, 111, 84-90. http://dx.doi.org/10.1016/S0169-328X(02)00672-1

[2] Schürks, M., Rist, P.M. and Kurth, T. (2009) MTHFR 677C > T and ACE D/I Polymorphisms in Migraine: A Systematic Review and Meta-Analysis. Headache, 50, 588-599. http://dx.doi.org/10.1111/j.1526-4610.2009.01570.x

[3] Gervil, M., Ulrich, V., Kaprio, J., Olesen, J. and Russell, M.B. (1999) The Relative Role of Genetic and Environmental Factors in Migraine without Aura. Neurology, 53, 995-999. http://dx.doi.org/10.1212/WNL.53.5.995

[4] Headache Classification Committee of the International Headache Society (IHS) (2013) International Classification of Headache Disorders. 3rd edition (beta version). Cephalalgia, 33, 645.

[5] Liu, R., Geng, P., Ma, M., Yu, S., Yang, M., He, M., Dong, Z. and Zhang, W. (2014) MTHFR C677T Polymorphism and Migraine Risk: A Meta-Analysis. Journal of the Neurological Sciences, 336, 68-73. http://dx.doi.org/10.1016/j.jns.2013.10.008

[6] Bahadir, A., Eroz, R. and Dikici, S. (2013) Investigation of MTHFR C677T Gene Polymorphism, Biochemical and Clinical Parameters in Turkish Migraine Patients: Association with Allodynia and Fatigue. Cellular and Molecular Neurobiology, 33, 1055-1063. http://dx.doi.org/10.1007/s10571-013-9972-1 
[7] Stuart, S., Cox, H.C., Lea, R.A. and Griffiths, L.R. (2012) The Role of the MTHFR Gene in Migraine. Headache, 52, 515-520. http://dx.doi.org/10.1111/j.1526-4610.2012.02106.x

[8] Wöber-Bingöl, C. (2013) Pharmacological Treatment of Acute Migraine in Adolescents and Children. Pediatric Drugs, 15, 235-246. http://dx.doi.org/10.1007/s40272-013-0019-3

[9] Kurth, T., Gaziano, J.M., Cook, N.R., Logroscino, G., Diener, H.C. and Buring, J.E. (2006) Migraine and Risk of Cardiovascular Disease in Women. JAMA, 296, 283-291. http://dx.doi.org/10.1001/jama.296.3.283

[10] Schürks, M., Rist, P.M., Bigal, M.E., Buring, J.E., Lipton, R.B. and Kurth, T. (2009) Migraine and Cardiovascular Disease: Systematic Review and Meta-Analysis. BMJ, 339, 1-11. http://dx.doi.org/10.1136/bmj.b3914

[11] Welch, K.M.A. and Levine, S.R. (1990) Migraine-Related Stroke in the Context of International Headache Society Classification of Head Pain. Arch Neurol, 47, 458-462. http://dx.doi.org/10.1001/archneur.1990.00530040114027

[12] Schürks, M., Kurth, T., Ridker, P.M., Buring, J.E. and Zee, R.Y. (2009) Association between Polymorphisms in the $\beta 2$-Adenoreceptor Gene and Migraine in Women. Headache, 49, 235-244. http://dx.doi.org/10.1111/j.1526-4610.2008.01207.x

[13] Pezzini, A., Grassi, M., Del Zotto, E., Giossi, A., Monastero, R., Dalla Volta, G., Archetti, S., Zavarise, P., Camarda, C., Gasparotti, R., Magoni, M., Camarda, R. and Padovani, A. (2007) Migraine Mediates the Influence of C677T MTHFR Genotypes on Ischemic Stroke Risk with a Stroke-Subtype Effect. Stroke, 38, 3145-3151. http://dx.doi.org/10.1161/STROKEAHA.107.491506

[14] Collaborative Group for the study of Stroke in Young Women (1975) Oral Contraceptives and Stroke in Young Women. Associated risk factors. JAMA, 231, 718-722. http://dx.doi.org/10.1001/jama.1975.03240190022010

[15] Kurth, T., Slomke, M.A., Kase, C.S., et al. (2005) Migraine, Headache, and the Risk of Stoke in Women: A Prospective Study. Neurology, 64, 129-134. http://dx.doi.org/10.1212/01.WNL.0000154528.21485.3A

[16] Stang, P.E., Carson, A.P., Rose, K.M., Mo, J., Ephross, S.A., Shahar, E., et al. (2005) Headache, Cerebrovascular Symptoms, and Stroke: The Atherosclerosis Risk in Communities Study. Neurology, 64, 1573-1577. http://dx.doi.org/10.1212/01.WNL.0000158326.31368.04

[17] An, X.K., Lu, C.X., Ma, Q.L., Zhang, X.R., Burgunder, J.M., Lin, Q. and Qu, H.L. (2013) Association of MTHFR C677T Polymorphisms with Susceptibility to Migraine in the Chinese Population. Neuroscience Letters, 549, 78-81. http://dx.doi.org/10.1016/j.neulet.2013.06.028

[18] Ueland, P.M. and Rozen, R. (2005) MTHFR Polymorphisms and Disease. Eurekah.com, Texas.

[19] Varga, E.A., Sturm, A.C., Misita, C.P. and Moll, S. (2005) Homocysteine and MTHFR Mutations: Relation to Thrombosis and Coronary Artery Disease. Circulation, 111, e289-e293. http://dx.doi.org/10.1161/01.CIR.0000165142.37711.E7

[20] Zonouzi, A.P., Chaparzadeh, N., Estiar, M.A., Sadaghiani, M.M., Farzadi, L., Ghasemzadeh, A., Sakhinia, M. and Sakhinia, E. (2012) Methylenetetrahydrofolate Reductase C677T and A1298C Mutations in Women with Recurrent Spontaneous Abortions in the Northwest of Iran. ISRN Obstetrics and Gynecology, 2012, Article ID 945486. http://dx.doi.org/10.5402/2012/945486

[21] Samaan, Z., Gaysina, D., Cohn-Woods, S., Craddock, N., Jones, L., Korszun, A., Owen, M., Mente, A., McGuffin, P. and Farmer, A. (2011) Methylenetetrahydrofolate Reductase Gene Variant (MTHFR C677T) and Migraine: A Case Control Study and Meta-Analysis. BMC Neurology, 11, 66. http://dx.doi.org/10.1186/1471-2377-11-66

[22] Liu, A., Menon, S., Colson, N.J., Quinlan, S., Cox, H., Peterson, M., Tiang, T., Haupt, L., Lea, R.A. and Griffiths, L.R. (2010) Analysis of the MTHFR C677T Variant with Migraine Phenotypes. BMC Research Notes, 3, 213. http://dx.doi.org/10.1186/1756-0500-3-213

[23] Zetterberg, H., Regland, B., Palmér, M., Ricksten, A., Palmqvist, L., Rymo, L., Arvanitis, D.A., Spandidos, D.A. and Blennow, K. (2002) Increased Frequency of Combined Methylenetetrahydrofolate Reductase C677T and A1298C Mutated Alleles in Spontaneously Aborted Embryos. European Journal of Human Genetics, 10, 113-118. http://dx.doi.org/10.1038/sj.ejhg.5200767

[24] Bottini, F., Celle, M.E., Calevo, M.G., Amato, S., Minniti, G., Montaldi, L., Pasquale, D.D., Cerone, R., Veneselli, E. and Molinari, A.C. (2006) Metabolic and Genetic Risk Factors for Migraine in Children. Cephalalgia, 26, 731-737. http://dx.doi.org/10.1111/j.1468-2982.2006.01107.x

[25] Herak, D.C., Antolic, M.R., Krleza, J.L., Pavic, M., Dodig, S., Duranovic, V., Brkic, A.B. and Zadro, R. (2007) Inherited Prothrombotic Risk Factors in Children With Stroke, Transient Ischemic Attack, or Migraine. Pediatrics, 123, e653-e660. http://dx.doi.org/10.1542/peds.2007-3737

[26] Rubino, E., Ferrero, M., Rainero, I., Binello, E., Vaula, G. and Pinessi, L. (2007) Association of the C677T Polymorphism in the MTHFR Gene with Migraine: A Meta-Analysis. Cephalalgia, 29, 818-825.

http://dx.doi.org/10.1111/j.1468-2982.2007.01400.x 
[27] Miller, S.A., Dykes, D.D. and Polesky, H.F. (1988) A Simple Salting out Procedure for Extracting DNA from Human Nucleated Cells. Nucleic Acids Research, 16, 1215-1216. http://dx.doi.org/10.1093/nar/16.3.1215

[28] Frosst, P., Blom, H.J., Milos, R., Goyette, P., Sheppard, C.A., Matthews, R.G., Boers, G.J., den Heijer, M., Kluijtmans, L.A., van den Heuvel, L.P. and Rozen, R.A. (1995) A Candidate Genetic Risk Factor for Vascular Disease: A Common Mutation in Methylenetetrahydrofolate Reductase. Nature Genetics, 10, 111-113. http://dx.doi.org/10.1038/ng0595-111

[29] Hanson, N.Q., Aras, O., Yang, F. and Tsai, M.Y. (2001) C677T and A1298C Polymorphisms of the Methylenetetrahydrofolate Reductase Gene: Incidence and Effect of Combined Genotypes on Plasma Fasting and Post-Methionine Load Homocysteine in Vascular Disease. Clinical Chemistry, 47, 661-666.

[30] Sekhar, M.S., Sasidharan, S., Joseph, S. and Kumar, A. (2012) Migraine Management: How Do the Adult and Pediatric Migraines Differ? Saudi Pharmaceutical Journal, 20, 1-7. http://dx.doi.org/10.1016/j.jsps.2011.07.001

[31] Lipton, R.B. and Bigal, M.E. (2005) The Epidemiology of Migraine. American Journal of Medicine, 118, 3S-10S.

[32] Ferrara, M., Capozzi, L., Bertocco, F., Ferrara, D. and Russo, R. (2012) Thrombophilic Gene Mutations in Children with Migraine. Hematology, 17, 115-117. http://dx.doi.org/10.1179/102453312X13221316478010

[33] Scher, A.I., Terwindt, G.M., Verschuren, W.M., Kruit, M.C., Blom, H.J., Kowa, H., Frants, R.R., van den Maagdenberg, A.M.J.M., van Buchem, M., Ferrari, M.D. and Launer, L.J. (2006) Migraine and MTHFR C677T Genotype in a Population-Based Sample. Annals of Neurology, 59, 372-375. http://dx.doi.org/10.1002/ana.20755

[34] Arruda, V.R., von Zuben, P.M., Chiaparini, L.C., Annichino-Bizzacchi, J.M. and Costa, F.F. (1997) The Mutation Ala677 $\rightarrow$ Val in the Methylene Tetrahydrofolate Reductase Gene: A Risk Factor for Arterial Disease and Venous Thrombosis. Thromb Haemost, 77, 818-821.

[35] Oterino, A., Valle, N., Bravo, Y., Munoz, P., Sanchez-Velasco, P., Ruiz-Alegria, C., Castillo, J., Leyva-Cobián, F., Vadillo, A. and Pascual J. (2004) MTHFR T677 Homozygosis Influences the Presence of Aura in Migraineurs. Cephalalgia, 24, 491-494. http://dx.doi.org/10.1111/j.1468-2982.2004.00692.x

[36] Ferro, A., Castro, M.J., Lemos, C., Santos, M., Sousa, A., Pereira-Monteiro, J., Sequeiros, J. and Maciel, P. (2008) The C677T Polymorphism in MTHFR Is Not Associated with Migraine in Portugal. Disease Markers, 25, 107-113. http://dx.doi.org/10.1155/2008/178679

[37] Azimova, J.E., Sergeev, A.V., Korobeynikova, L.A., Kondratieva, N.S., Kokaeva, Z.G., Shaikhaev, G.O., Skorobogatykh, K.V., Fokina, N.M., Tabeeva, G.R. and Klimov, E.A. (2013) Effects of MTHFR Gene Polymorphism on the Clinical and Electrophysiological Characteristics of Migraine. BMC Neurology, 13, 103.

http://www.biomedcentral.com/1471-2377/13/103 
Scientific Research Publishing (SCIRP) is one of the largest Open Access journal publishers. It is currently publishing more than 200 open access, online, peer-reviewed journals covering a wide range of academic disciplines. SCIRP serves the worldwide academic communities and contributes to the progress and application of science with its publication.

Other selected journals from SCIRP are listed as below. Submit your manuscript to us via either submit@scirp.org or Online Submission Portal.
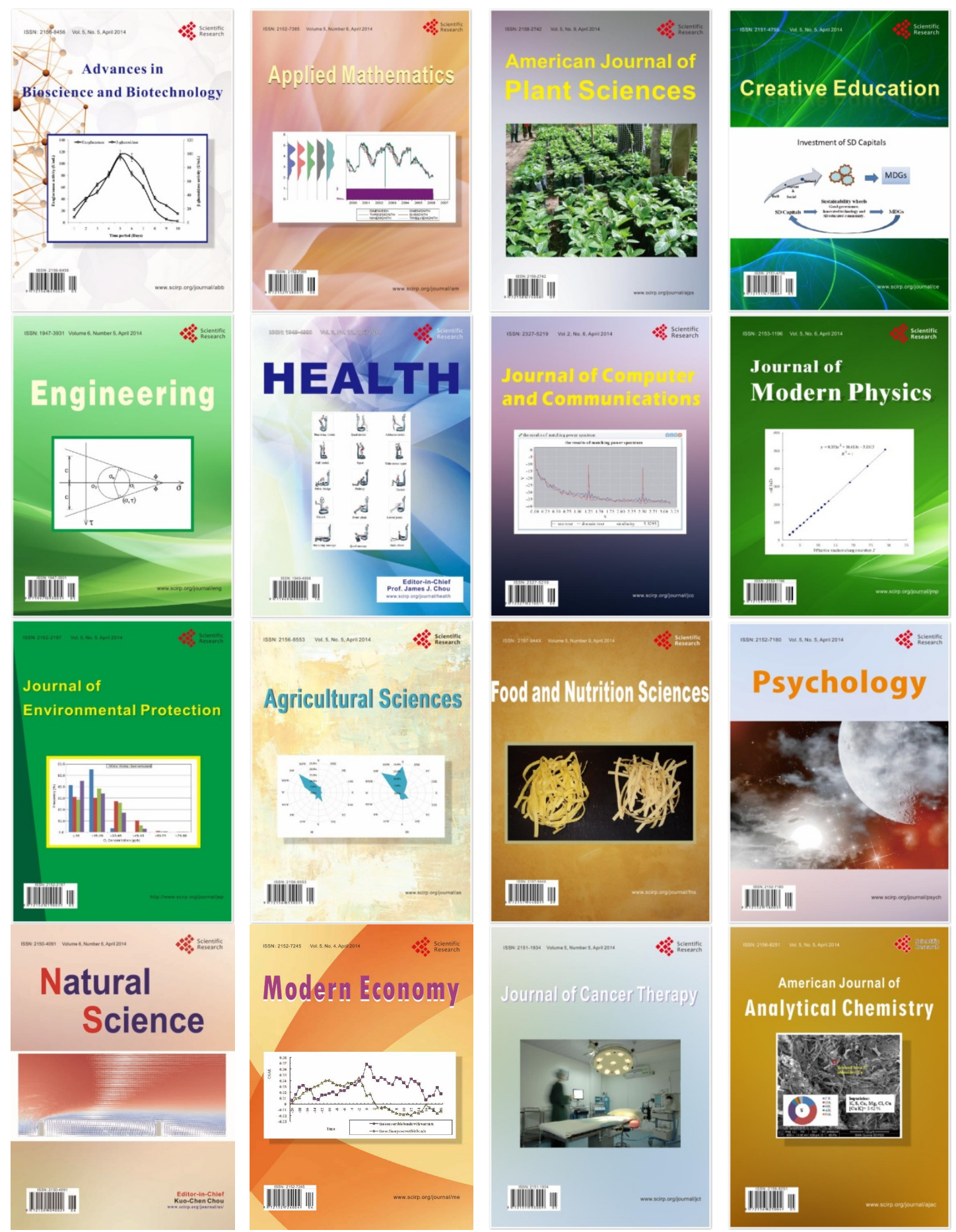